\title{
Cost analysis of surgical options for benign disease: Implications for value
}

\author{
David-Dan Nguyen'; Kevin C. Zorn, MD, FRCSC; Naeem Bhojani, MD, FRCSC² \\ 'Faculty of Medicine, McGill University, Montreal, QC, Canada; '2Division of Urology, Université de Montréal Health Centre, Montreal, QC, Canada
}

Cite as: Can Urol Assoc J 2018;12(12):388-9. http://dx.doi.org/10.5489/cuaj.5730

See related article on page 382

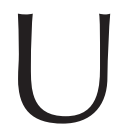
nderstanding the cost of surgical care is an important step toward containing it. At its core, the deployment of health services is a question of making choices with underlying tradeoffs in mind. Urologists are regularly confronted by such questioning. One needs only to contemplate the surgical armamentarium of lasers, robots, and resective tools available for the treatment of lower urinary tract symptoms (LUTS) due to benign prostatic hyperplasia (BPH). When multiple alternatives exist, which one do we choose? At the practitioner-level, the efficacy of the modality, as well as the training and personal comfort with the technique, are unavoidable considerations. But at the healthcare-system level, it is imperative that allocation of funding and training of future surgeons also take into account the economic burden of care. With this mindset, clinical performance of a tool must be weighed against its cost. Value, defined as the health outcomes achieved per dollar spent, ${ }^{1}$ should determine if we collectively adopt one intervention or another.

Masucci et al pursued such an endeavor in the context of LUTS due to BPH and evaluated the cost of three surgical approaches. Examining Greenlight photoselective vaporization of the prostate (PVP), transurethral resection of the prostate (TURP), and bipolar TURP, they conducted a descriptive costing analysis from the hospital's point of view. The total cost of PVP was $\$ 3836$ per patient compared to $\$ 4963$ for TURP and $\$ 4978$ for bipolar TURP. The savings were mainly attributed to the higher proportion of PVP performed as day surgery, avoiding costly inpatient hospitalizations. ${ }^{2}$

To hypothesize on the implications of their findings, we must first break down how the authors measured cost. The analysis was conducted from the perspective of a tertiary academic medical centre. It excluded expenses such as the cost of training surgeons (burden on the system), out-of-pocket expenditure for travel to the medical centre (burden on the patient), and the environmental impacts of non-reusable equipment (burden on society), among others. The authors included costs beyond those of the operating room, such as expenses relating to readmissions at 30 and 60 days, further strengthening their findings. Considering the variable definitions of cost in the literature, it is essential to appropriately contextualize these findings when comparing them to previous evidence.

When appreciating this paper by Masucci et al, the reader must acknowledge the implications of a two-year study period conducted at an academic centre. In fact, a significant conceptual hurdle is understanding the effect of volume and time on cost. For example, it has been noted that the high-volume use of robotic surgery absorbed the expensive initial purchase of the system and amounted to a lower cost than laparoscopy. ${ }^{3}$ It is also well-established that hospital case volume is directly correlated with better outcomes for surgical procedures, ${ }^{4}$ further reducing the potential complications leading to costly readmissions.

Within the scope of their analysis, PVP is a more financially sound option compared to TURP. In order to formulate a full economic comparison, which was out of the scope of this study, one must consider the effectiveness and the utility of each approach. Considering the growing body of evidence supporting the non-inferiority of PVP to TURP when treating $\mathrm{BPH}^{5-7}$ Masucci et al's results further confirm the hypothesis that PVP provides more value than TURP from the perspective of the hospital. Whether or not this economic benefit can be translated to the healthcare system as a whole and the individual patient remains to be confirmed. Cost analyses of subgroups where PVP confers added value, such as in the growing population of men at high risk of bleeding on oral anticoagulants, ${ }^{8-10}$ should also be explored.

Furthermore, again outside the scope of this study, it would have been interesting to compare the cost of these procedures with that of holmium laser enucleation of the prostate (HoLEP) for BPH. Clinical outcomes for HoLEP, which are prostate volume-independent, are equivalent if not superior to TURP and PVP. ${ }^{11-16}$ Additionally, in contrast to PVP, all instrumentation (laser fiber and morcellator blades) are reusable. ${ }^{16}$ 
Surgical care in Canada is budget-dependent; to maximize operating room resources while also maximizing the patient's well-being, we must weigh the cost of a procedure against its benefits and utility. As guardians of the healthcare system, we must remain aware of the inherent economic burden of the procedures we decide to use and invest in. When spending additional resources on new interventions, we must first determine if the benefits, clinical or otherwise, outweigh the cost and other tradeoffs of reallocating limited funds. Following Masucci et al's findings and the growing body of evidence on the surgical management of LUTS due to $\mathrm{BPH}$, a strong case can be made for the higher value of PVP in comparison to TURP.

Competing interests: Dr. Zorn has received honoraria as a proctor/lecturer for Greenlight from Boston Scientific and participated in the WATER II trial with aquablation supported by Procept Biorobotics. Dr. Bhojani participated in the WATER II trial with aquablation supported by Procept Biorobotics. Mr. Nguyen reports no competing personal or financial interests.

\section{References}

1. Porter ME, Teisberg EO. Redefining healthcare: Creating value-based competition on results. Harvard Business Press; 2006.

2. Masucci L, Erman A, Krahn MD, et al. Cost analysis of Greenlight photoselective vaporization of the prostate compared to transurethral resection of the prostate for benign prostatic hyperplasia. Can Urol Assoc J 2018;12:382-7. https://doi.org/10.5489/cuai.5267

3. Boggess JF. Robotic surgery in gynecologic oncology: Evolution of a new surgical paradigm. J Robot Surg 2007;1:31-7. htrps://doi.org/10.1007/s11701-007-0011-4

4. Begg CB, Cramer LD, Hoskins WJ, et al. Impact of hospital volume on operative mortality for major cance surgery. JAMA 1998;280:1747. https://doi.org/10.1001/jama.280.20.1747

5. Bouchier-Hayes DM, Van Appledorn S, Bugeja P, et al. A randomized trial of photoselective vaporization of the prostate using the 80-W potassium--itanyl-phosphate laser vs. transurethral prostatectomy, with a one-year followup. BJU Int 2010;105:964-9. https://doi.org/10.1111/i.1464-410X.2009.08961.X
6. Thomas JA, Tubaro A, Barber N, et al. A multicenter, randomized, non-inferiority trial comparing GreenlightXPS laser vaporization of the prostate and transurethral resection of the prostate for the treatment of benign prostatic obstruction: Two-year outcomes of the GOLLATH study. Eur Urol 2016;69:94-102. https://doi.org/10.1016/i.eururo.2015.07.054

7. Lin $Y, W \cup X, X \cup A$, et al. Transurethral enucleation of the prostate vs. transvesical open prostatectomy for large benign prostatic hyperplasia: A systematic review and meta-analysis of randomized controlled trials. World J Urol 2016;34:1207-19. https://doi.org/10.1007/s00345-015-1735-9

8. Ruszat R, Wyler $S$, Forster $T$, et al. Safety and effectiveness of photoselective vaporization of the prostate (PVP) in patients on ongoing oral anticoagulation. Eur Urol 2007;51:1031-41. https://doi.org/10.1016/i.eururo.2006.08.006

9. Woo H, Reich 0, Bachmann A, et al. Outcome of Greenlight HPS 120-W laser therapy in specific patient populations: Those in retention, on anticoagulants, and with large prostates ( $\geq 80 \mathrm{ml}$ ). Eur Urol Suppl 2008;7:378-83. https://doi.org/10.1016/i.eursup.2008.01.016

10. Lee DJ, Rieken M, Halpern J, et al. Laser vaporization of the prostate with the 180-W XPS-Greenlight laser in patients with ongoing platelet aggregation inhibition and oral anticoagulation. Urology 2016;91:167-73. https://doi.org/10.1016/i.urology.2016.01.021

11. Wilson LC, Gilling PJ, Williams A, et al. A randomized trial comparing holmium laser enucleation vs. transurethral resection in the treatment of prostates larger than $40 \mathrm{~g}$ : Results at two years. Eur Urol 2006:50:569-73. https://doi.org/10.1016/i.eururo.2006.04.002

12. Kuntz RM, Ahyai $S$, Lehrich $K$, et al. Transurethral holmium laser enucleation of the prostate vs. transurethral electrocautery resection of the prostate: A randomized prospective trial in 200 patients. J Urol 2004;172:1012-16. https://doi.org/10.1097/01.ju.0000136218.11998.9e

13. Ahyai $S A$, Gilling P, Kaplan SA, et al. Meta-analysis of functional outcomes and complications following transurethral procedures for lower urinary tract symptoms resulting from benign prostatic enlargement. Eur Urol 2010;58:384-97. https://doi.org/10.1016/i.eururo.2010.06.005

14. Yin L, Teng J, Huang $(-\mathrm{J}$, et al. Holmium laser enucleation of the prostate vs. transurethral resection of the prostate: A systematic review and meta-analysis of randomized controlled trials. J Endourol 2013;27:60411. https://doi.org/10.1089/end.2012.0505

15. Gilling PJ, Wilson LC, King CJ, et al. Long-term results of a randomized trial comparing holmium laser enucleation of the prostate and transurethral resection of the prostate: Results at 7 years. BJU Int 2012;109:408-11. htrps://doi.org/10.1111/i.1464-410X.2011.10359.x

16. Elshal AM, Elkoushy MA, El-Nahas AR, et al. Greenlight" laser (XPS) photoselective vapo-enucleation vs. holmium laser enucleation of the prostate for the treatment of symptomatic benign prostatic hyperplasia: A randomized controlled study. J Urol 2015;193:927-34. https://doi.org/10.1016/i.juro.2014.09.097

Correspondence: Dr. Naeem Bhojani, Division of Urology, Université de Montréal Health Centre, Montreal, QC, Canada 